\title{
Accumulative Calcium Ion Release \& EDX Analysis from New Generation Self-Adhesive Resin Cement
}

\author{
Zahra`a A. AL-Kataan ${ }^{1}$, Ali. M. AL-Naimi ${ }^{2}$ \\ ${ }^{I}$ BDS, Higher Diploma in conservative dentistry (Master student): Ministry of health -Nineveh Health Directorate. \\ ${ }^{2} B D S, M S c$, PhD (Lecturer): Department of Conservative Dentistry, Collage of Dentistry, University of Mosul. \\ "Corresponding author. Email: Zahraa.dep38@student.uomosul.edu.iq
}

\begin{abstract}
This study aimed to evaluate accumulative calcium ion release from new generation calcium releasing self-adhesive resin cement (TheraCem ${ }^{\circledR C} \mathrm{Ca}$ ) in different time and in two different $\mathrm{pH}$, and the effect of calcium addition on the substrate. MATERIAL AND METHODS: Six samples of self-adhesive resin cement, TheraCem®Ca cylinder in shaped of diameter $3.7 \mathrm{~mm}$ and height $3 \mathrm{~mm}$, after material curing, the calcium release measure in two different $\mathrm{pH}$. Then three specimens for alkaline $\mathrm{pH} 7$ and 3 specimens for acidic $\mathrm{pH}$ 5. Calcium ion measurement take in time period of one day, seven days, fourteen days, twenty one days, twenty eight days, using colorimetric method to evaluate the amount of calcium ion release using spectrophotometer. Three TheraCem ${ }^{\circledR C}$ a self-adhesive resin cement specimens bonded to three different substrate (enamel, dentin and zirconia) after 24 hours, the cement removed and the specimen send with control specimens(enamel, dentin, and zirconia without any treatment) to Energy Dispersive x-ray (EDX) to analyze effect of the calcium addition on these substrates. RESULTS: The result of this study proved that, ability of self-adhesive resin cement to release calcium over period 28 days. In four time points there were no significant difference in calcium ion release, but in 28day time period there were significant reduction calcium release from the cement at $\mathrm{pH} 5$ in comparison to $\mathrm{pH} 7$ at $\mathrm{p} \leq 0.05$. CONCLUSIONS: Self-adhesive resin cement has ability to release calcium ion in time period of 28 days, and the effect of the change in environmental $\mathrm{pH}$ not occur until day 28 of the release, EDX analysis showed the resin cement contain phosphate ion which increase effectiveness of calcium ion release from the cement.
\end{abstract}

Keywords: Ca ion release self-adhesive rein cement, remineralisation, neutralization.

\section{INTRODUCTION}

Dental caries (DC) considered as the most prevalent dental health problem, because it affected nearly all age groups. It is multifactorial disease (1), many factors contributed in it' s development such as: cariogenicmicroorganism, substrate, host (teeth) and time. All these factors combined to cause continuous mineral loss and permanent destruction of tooth structure, DC occur due to loss balance between demineralization and remineralization process, when acids from cariogenic microorganism present in dental plaque released and lead to drop of the oral environmental $\mathrm{pH}$, which allow other cariogenic species such as Streptococcus mutans to develop caries lesion (2) .
Caries around margin of existing dental restoration are one of the most critical aspect affecting indirect restoration, marginal discrepancy may exposed dental cement to the oral environment and this increasing the risk of demineralization attack (3). Marginal gap allow food accumulation around the crown restoration. Bacteria from dental plaque penetrated the tooth cement interface change the $\mathrm{pH}$ of oral environment around the margin of existing restoration. Finally, caries lesion is formed (4-6). Saliva neutralize the $\mathrm{pH}$ and mechanically clean the teeth in the oral cavity. $\mathrm{pH}$ control the process of calcium and phosphate loss and gain from the tooth structure (7). Saliva and biofilm fluid have high concentration of calcium and phosphate, which lead to continually ion deposited on enamel surface (8). But continuous production of bacterial acid lead to increase 
demineralization of calcium and phosphate, demineralization occur when $\mathrm{pH}$ drop below 6.5 for dentin and 5.5for enamel (9).

Dental cements act as connection between the tooth structure and the crown material. The development of dental cements containing an antibacterial monomer, calcium and phosphate Nano-particles used to reduce dental caries and to induce re-mineralization, dental cements consider ideal when it possess the following properties biocompatibility, antibacterial activity, low film thickness, low viscosity, minimal solubility, sufficient working time, no micro-leakage, have comparable strength and stiffness to dentin $(3,10)$. Calcium silicate based-cements material are bioactive and bio-reactive material capable of forming apatite by using calcium silicate or calcium aluminates (11).

Hydration of bioactive material lead to the release of a number of ions during setting stage and that reaction on the surface of the materials can alter concentration of the dissolve ions which in turn triggers an intracellular and extracellular response, which lead to remineralization, calcium silicate containing cement have capacity to release hydroxyl $(\mathrm{OH})$ ion, and calcium ion and produced apatite like precipitates, when they come in contact with phosphate containing physiological fluid (12-17).

This study aims to evaluate accumulative calcium ion release from new generation of self-adhesive resin cement TheraCem ${ }^{\circledR C a}$ in different time and at two different $\mathrm{pH}$ condition. The null hypothesis there is no significant differences in calcium ion release in timeperiod and at two different $\mathrm{pH}$ conditions, and there is no effect of calcium ion addition in self- adhesive resin cement.

\section{MATERIAL AND METHODS}

Estimation of total Calcium in TheraCemCa Sample of $0.0338 \mathrm{gr}$ putted in ceramic basin and placed in muffle furnace at $700{ }^{\circ} \mathrm{C}$ for at least one hour to break down all organic materials of the resin cement, then the material crushed to increase the surface area, and add 20 $\mathrm{ml}$ of concentrated $\mathrm{H} 2 \mathrm{SO} 4,1: 1$, and after filtering the material, the volume completed to $20 \mathrm{ml}$. To analyze total calcium from TheraCem ${ }^{\circledR C a}$ using PFP7 Flame photometer [JENWay]. Starting with preparation of standard solution of $1000 \mathrm{ppm}$ of $\mathrm{CaCl} 2$ and by mathematical equation calculate the exacted calcium ion in the material.

Six samples of TheraCem ${ }^{\circledR C a}$ divided to two group of three samples each at 7 and $5 \mathrm{pH}$. The samples prepared in Teflon mold of internal diameter of $3.7 \mathrm{~mm}$ and height of $3 \mathrm{~mm}$. After material curing for $40 \mathrm{sec}$. by super LED, light cure, unite. Samples kept in phosphate buffer solution and the $\mathrm{pH}$ adjusted to the desired $\mathrm{pH}$ using hydrochloric acid. Calcium release measured by calcium CPC method from Biolabo, France (Ref-80004) for 1 day, 7 days, 14 days, 21 days, and 28 days at $570 \mathrm{~nm}$.

Three control specimens(without any treatment) form enamel, dentin, and zirconia, with three TheraCem®Ca self-adhesive resin cement, bonded to three different substrate (enamel, dentin, and zirconia), after 24hours the cement removed and the specimens send to field emission scanning electron microscope, with EDS MIRA3, TESCAN, CU filament, 0.154nm, Czech Republic (EDX analysis) to detect the effect of calcium addition on these substrates.

Data were represent as mean $\pm \mathrm{SD}$; data analyzed using Excel 2010. Paired two t-test were apply to show the degree of significance at $\mathrm{p} \leq 0.05$ and less.

\section{RESULTS}

Calcium ion release from TheraCem ${ }^{\circledR C a}$ selfadhesive resin cement, over the time period of 1 day, 7 days, 14 days, 21 days, 28 days, at two different $\mathrm{pH}$ (7 and 5 respectively) as shown in (Table 1).

Table 1. Calcium ion release at $\mathrm{pH}$ (7 and 5) in vitrofor different time intervals.

\begin{tabular}{|c|c|c|c|}
\hline Time period & $\begin{array}{c}\text { pH7 (Mean } \pm \\
\text { SD })\end{array}$ & pH5 $($ Mean \pm SD) & $\begin{array}{c}P \text { - } \\
\text { value }\end{array}$ \\
\hline One day & $52.7 \pm 6$ & $44.67 \pm 2.51$ & 0.101 \\
\hline Seven days & $85 \pm 13.6$ & $85.67 \pm 3.21$ & 0.96 \\
\hline $\begin{array}{c}\text { Fourteen } \\
\text { days }\end{array}$ & $111 \pm 3.5$ & $107.33 \pm 2.08$ & 0.16 \\
\hline $\begin{array}{c}\text { Twenty one } \\
\text { days }\end{array}$ & $129.7 \pm 5.1$ & $122 \pm 4.36$ & 0.11 \\
\hline $\begin{array}{c}\text { Twenty eight } \\
\text { days }\end{array}$ & $149 \pm 3$ & $136.67 \pm 2.08$ & 0.00 \\
\hline
\end{tabular}

Paired two t-test show no significant difference in calcium ion release at level( $\mathrm{p}>0.05)$ for 1 day, 7 days, 14 days, 21 days and at $\mathrm{pH}$ (7 and 5 Respectively), but show high significant difference at the level of $(p \leq 0.05)$ for calcium ion release in ppm in 28 days-time period Figure(1). 


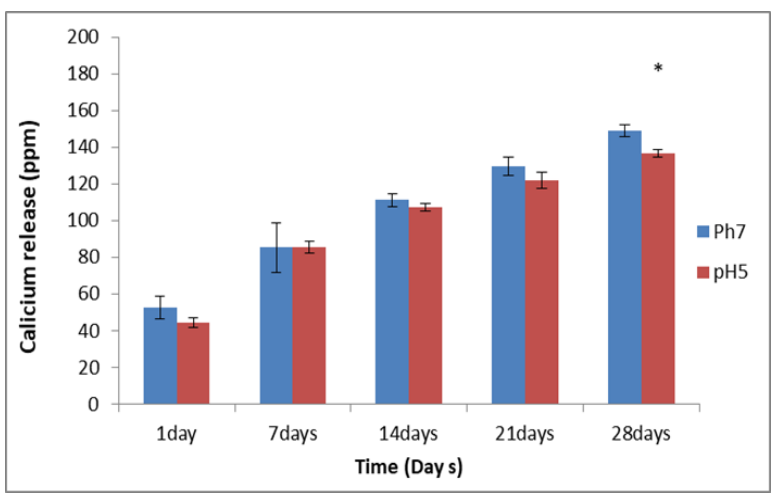

Figure 1 Calcium ion release form TheraCem ${ }^{\circledR} \mathrm{Ca}$ over 28 days interval at pH 7 (Blue) and 5 (Red).

EDX analysis of TheraCem ${ }^{\circledR C} \mathrm{Ca}$ bonded to three different substrate showed that for enamel $\mathrm{Ca}+$ ion form (3.33Wt \%), for dentin $\mathrm{Ca}+$ ion form $(2.48 \mathrm{Wt} \%)$, and for zirconia $(0.03 \mathrm{Wt} \%)$. Also Carbon and Nitrogen form highest weight percent $(\mathrm{Wt} \%)$ from the resin components of the cement, $\mathrm{P}$ ion for enamel substrate $(4.83 \mathrm{Wt} \%)$, for dentin $(1.97 \mathrm{Wt} \%)$, for zirconia $(0.12$ $\mathrm{Wt} \%$ ) enamel and dentin contain calcium and phosphate ion in form of hydroxyapatite, but zirconia devoid of them, $\mathrm{SiO} 2$ and traces of $\mathrm{Na}, \mathrm{Mg}, \mathrm{F}$ ion in form of $\mathrm{CaF} 2, \mathrm{~S}, \mathrm{Sr}, \mathrm{Br}$ are additive from the cements material. In order to determine the $\mathrm{Ca}$ element composition of individual tissue after one day of application of TheraCem®Ca; Energy dispersive X-ray (EDX) analysis was perform on different substrates (enamel, dentin, and zirconia). The results of EDX showed that in both enamel and dentine; $\mathrm{Ca}$ ion concentration decreased due to action of the acidic functional monomer, which cause demineralization of tooth surface for 1st 24hoursof cement application, the presence of $\mathrm{Ca}+$ and $\mathrm{P}+$ ions on zirconia surface due to the cement application.
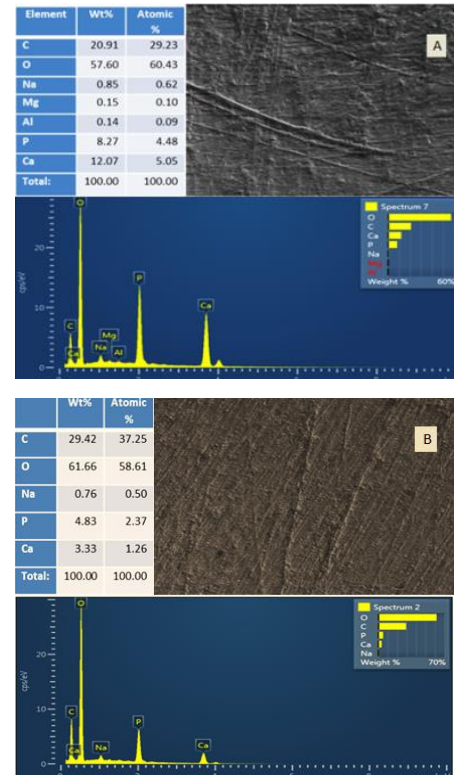

Figure 2 EDX analysis of TheraCem ${ }^{\circledR C a}$ resin cement (A) Enamel control specimen. (B) TheraCem®Ca bonded to enamel

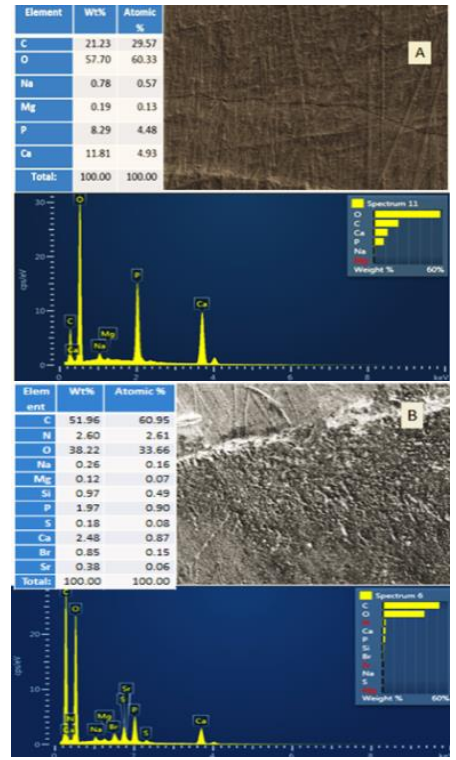

Figure 3 EDX analysis of TheraCem ${ }^{\circledR C a}$ resin cement(A)Dentin control specimen. (B)TheraCem ${ }^{\circledR C a}$ bonded to dentin. 

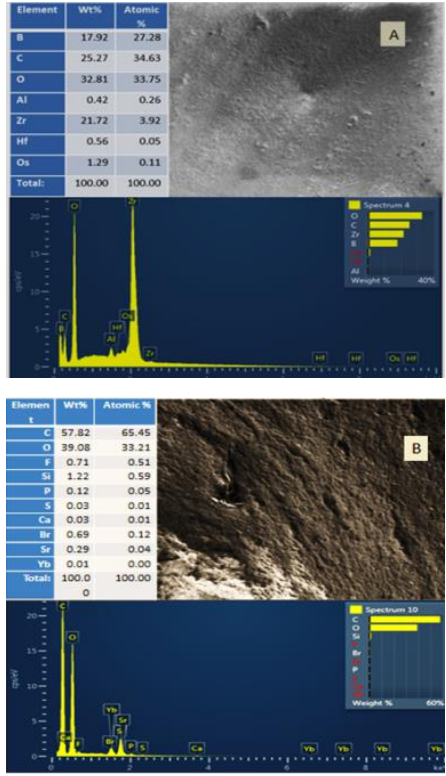

Figure 4 EDX analysis of TheraCem ${ }^{\circledR C a}$ resin cement(A) Zirconia control specimen(B) TheraCem® $\mathrm{Ca}$ bonded to zirconia

\section{DISCCSION}

Bioactive material is heterogeneous group of materials, employ different strategies with aim of prevent formation of secondary caries, these material bioactive effects can be either anti- microbial activity or produce re -mineralization $(18,19)$. Re-mineralization process, based on soluble fillers which release calcium, phosphate, fluoride and other ion (20), these ions can be incorporated into demineralized dental tissues $(21,22)$, or precipitated within the defect at the interface between the tooth and the restoration, and contributing to its sealing (23). All calcium silicate containing cements such as mineral trioxide aggregate (MTA) and TheraCemCa formulations leached large amount of $\mathrm{Ca}+$ ion, hydration reaction of the calcium silicate particles triggers the dissolution of their surface, and formation of calcium silicate hydrate gel and $\mathrm{Ca}(\mathrm{OH}) 2$ together with release of $\mathrm{Ca}+$ and $\mathrm{OH}-$ ion (24). Self-adhesive resin cements (SARCs) such as: TheraCemCa contain functional phosphoric acidic monomer group $(25,26)$, which demineralize enamel and dentin, provide adhesion to the tooth surface through micromechanical retention and copolymerize with crosslinking monomer (27). Initially, the cement become highly acidic and hydrophilic for bonding as well as for adaptation to the tooth surface, by providing demineralization to the tooth surface (28), while the chemical reaction between the acidic monomers with apatite and the ion release from filler particles $(\mathrm{Ca}+, \mathrm{Ph}+)$ neutralize the remaining acid groups (25). the structure become neutral and hydrophobic, TheraCemCa induce strong neutralization reaction due to mineral contained, resulting in low hygroscopic expansion stresses this mainly of high benefit in case when there is no dental substrate (only restorative material) to help in neutralization process. This process relies exclusively on the intrinsic self-neutralization reaction of the cement $(29,30)$, the study proved that, there is continuous $\mathrm{Ca}+$ ion released from TheraCemCa in time period of 28 days, we partially reject the null hypotheses because for (1day,7days, 14days, 21days) there is no significant difference in $\mathrm{Ca}+$ ion release between the different $\mathrm{pH}$, but at 28days there is significant decrease in ion release in acidic $\mathrm{pH}$, occur due to TheraCemCa was more resistant to aging in an acidic environment, because it contains calcium silicate, after mixing, reaction started at $\mathrm{pH}(4)$ and stabilized at $\mathrm{pH}(9)$ after 24hours (31), neutralization provides low water absorption and minimum hydrolytic degradation $(25,32,26)$ beside the other benefits of remineralization and fill the gaps between the tooth and restoration. EDX analysis, explain that TheraCemCa self-adhesive resin cement contain $\mathrm{Ca}+$ and phosphate ion in weight percent differ from one substrate to other, related to amount of mineral dissolved by functional acidic monomer and the filler released from the cement itself, in case of zirconia this material devoid of $\mathrm{Ca}+$ and phosphate ions so the presence of this element on its surface related to the cement main components as well as fluoride ion. All these ion help in re-mineralization process as mention before.

\section{CONCLUSIONS}

With limitation of the study, self-adhesive resin cement TheraCem ${ }^{\circledR C a}$ has ability to continuous calcium ion release for 28 days period, there is significant decrease in ion release after 28days, due to the type of filler contained, EDX analysis showed the resin cement contain phosphate ion which increase effectiveness of calcium ion release from the cement.

\section{REFERENCES}

[1] Abou Neel E.A, Aljabo A., StrangeA., Ibrahim S., CoathupM., Young A.M, BozecL., MuderaV. Demineralization-remineralization dynamics in teeth and bone. Int. J. Nanomed. 2016;(11): 4743-4763.

[2] Marsh P.D. Dental plaque as a biofilm and a microbial community - implications for health and disease. BMC Oral Health. 2006; (Suppl 1) S14

[3] Rosenstiel, S.F., Land, M.F., Crispin, B.J. Dental luting agents: A review of the current literature. J. Prosthet. Dent. 1998; (80): 280-301. 
[4] Mjör, I.A.; Jokstad, A.; Qvist, V. Longevity of posterior restorations. Int. Dent. J. 1990; (40): 1117.

[5] Jokstad, A., Bayne, S., Blunck, U., Tyas, M., Wilson N. Quality of dental restorations. FDI Commission Project 2-95. Int. Dent. J. 2001;( 51): 117-158.

[6] Jokstad, A. Secondary caries and microleakage. Dent. Mater.2016; (32): 11-25.

[7] Papadimitriou K, Alegria A., BronA.P., de Angelis M., GobbettiM.,Kleerebezem M., Lemos A.J, Linares D., Ross P., Stanton C., TurroniF., VanSinderen D., Varmanen P., Ventura M., Zuniga M., Tsakalidou E., KokJ. Stress physiology of lactic acid bacteria. Microbiol. Mol.Biol. Rev.2016; ( 80): 837-890.

[8] CuryJ.A., Tenuta L.M. Enamel remineralization: controlling the caries disease or treating early caries lesions? Braz. Oral Res. 2009; (23): (Suppl 1) $23-30$.

[9] Leitao T.J., Cury J.A., Tenuta L.M.A. Kinetics of calcium binding to dental biofilm bacteria. PLoS One 2018; (13): e0191-284.

[10] Unosson E., Cai Y., Jiang X., Lööf J., Welch K., Engqvist H . Antibacterial properties of dental luting agents: Potential to hinder the development of secondary caries. Int. J. Dent. 2012: 495- 529.

[11] Camilleri J. "Hydration characteristics of biodentine and theracal used as pulp capping materials" Dental Materials. 2014; vol (30) no. 7, pp. 709-715.

[12] Sarkar N.K., Caicedo R., Ritwik P., Moiseyeva R., Kawashima I. Physicochemical basis of the biologic properties of mineral trioxide aggregate. Journal of Endodontics. 2005; (31): 97-100.

[13] Bozeman T.B., Lemon R.R., Eleazer P.D. Elemental analysis of crystal precipitate from gray and white MTA. Journal of Endodontics. 2006; (32): 425-8.

14.Reyes-Carmona JF, Felippe MS, Felippe WT.(2009) Bio mineralization ability and interaction of mineral trioxide aggregate and white Portland cement with dentin in a phosphate-containing fluid. J Endod.2009; (35):731-736.

[15] Gandolfi MG, Taddei P, Tinti A, Prati C (2010) Apatite-forming ability (bioactivity) of ProRoot MTA. Int. Endodo J. 2010;(43): 917-29.
[16] Han L, Okiji T. Bioactivity evaluation of three calcium silicate-based endodontic materials. Int. Endod J.2013; (46):808-814.

[17] Han L, Kodama S, Okiji T. Evaluation of calcium releasing and apatite-forming abilities of fastsetting calcium silicate-based endodontic materials. Int. Endod J. 2015; (48): 124-30.

[18] Xu HH, Weir MD, Sun L, Moreau JL, Takagi S, Chow LC, Antonucci JM.

Strong nano-composites with $\mathrm{Ca}, \mathrm{PO}(4)$, and $\mathrm{F}$ release for caries inhibition. J Dent Res.2010; (89):19-28.

[19] Mehdawi I.M., Pratten J,, Spratt D.A., Knowles J.C., Young A.M. High strength re-mineralizing, antibacterial dental composites with reactive calcium phosphates. Dent Mater. 2013; 29(4):47384.

[20] Jandt K.D., Sigusch B.W. Future perspectives of resin-based dental materials. Dent Mater. 2009; 25(8):1001-6.

[21] Sauro S., Osorio R., Osorio E., Watson T.F., Toledano M. Novel light-curable materials containing experimental bioactive micro-fillers remineralise mineral-depleted bonded-dentine interfaces. J BiomaterSciPolym Ed. 2013 ; 24(8):940-56.

[22] Milly H., Festy F., Watson T.F., Thompson I., Banerjee A. Enamel white spot lesions canremineralise using bio-active glass and polyacrylic acid-modified bio-active glass powders. J Dent. 2014;42(2):158-66.

[23] Khvostenko D., Hilton T.J., Ferracane J.L., Mitchell J.C., Kruzic J.J. Bioactive glass fillersreduce bacterial penetration into marginal gaps for composite restorations. Dent Mater. 2016;32(1):73-81

[24] Gandolfi, M. G.,Siboni F., BoteroT., Bossu M., Ricctitiello F., Prati C. Calcium silicate and calcium hydroxide materials for pulp capping: biointeractivity, porosity, solubility and bioactivity of current formulations. J. Appl. Biomater. Funct. Mater.2015; (13): 43-60 .

[25] Ferracane J. L., Stansbury J. W., Burke F.J.(2011). Self-adhesive resin cements- chemistry, properties and clinical considerations. J Oral Rehabil. 2011; 38 (4): 295-314.

[26] Manso A. P., Carvalho R. M. Dental Cements for Luting and Bonding Restorations: Self-Adhesive Resin Cements. Dent ClinNorth Am. 2017; 61 (4): 821-34. 
[27] Pilo R., Papadogiannis D., Zinelis S., EliadesG. Setting characteristics and mechanical properties of self-adhesive resin luting agents. Dent Mater. 2017; 33 (3): 344-57.

[28] Zorzin J., Petschelt A., Ebert J., Lohbauer U. pH neutralization and influence on mechanical strength in self-adhesive resin luting agents. Dental Materials.2012; 28 (6): 672-9.

[29] Sterzenbach G., Karajouli G., Tunjan R., Spintig T., Bitter K., Naumann M. Damage of lithium di silicate all-ceramic restorations by an experimental self- adhesive resin cement used as core build ups. clin Oral Investig .2015; 19(2) :281-8.

[30] Roedel L., Bednarzig V., Belli R. Self- adhesive cements pH-neutralization hydrophilicity and hydroscopic expiation stress. Clin Oral Investig. 2016; (16) 21:1735-4.

[31] Chen L., Yang J., Wang J.R., Suh B.I. Physical and biological properties of a newly developed calcium silicate-basedself-adhesive cement. Am J Dent. 2018 ; 31(2): 86-90.

[32] Marghalani H.Y.(2012). Sorption and solubility characteristics of self-adhesive resin cements. Dent Mater. 2012; 28 (10): e187-98. 